\title{
SANTA MARÍA DE WAMBA, ENTRE SU PASADO Y EL FUTURO
}

\author{
VALLADOLID/ESPAÑA
}

(SANTA MARIA OF WAMBA, BETWEEN ITS PAST AND THE FUTURE. VALLADOLID/SPAIN)

José L. de la Quintana Gordon y José R. Boned Colera, Arquitectos

$128-43$

Fecha de recepción: 11-111-92

\section{RESUMEN}

El monasterio de Santa María, Monumento Nacional desde Junio de 1931, se desarrolló entre los siglos X y XVIII llegando a ser un importante centro espiritual y administrativo. Durante ese proceso, cada adición histórica al conjunto, logró reflejar los planteamientos compositivos y constructivos de su tiempo sin destruir la organización espacial original.

Sin embargo, el abandono derivado de las exclaustraciones decimonónicas y la descomposición de las estructuras calizas a causa de la humedad del subsuelo,

desencadenaron un proceso de deterioro que puso a la abadia al borde de la ruina y provocó la pérdida de gran parte de su patrimonio mueble. Pese a ello, la iglesia conservó el culto permanentemente.

En 1984 la Junta de Castilla y León acometió la restauración del monumento. Las obras y los procesos paralelos de investigación y documentación, se desarrollaron durante seis años con una estrecha cooperación entre especialistas. Se coronó así una etapa más en la vida del edificio, en la que se obtuvieron datos desconocidos acerca del orden espacial original (que pudo ser clarificado), y se prestó gran atención al encuentro de los elementos nuevos con los históricos.

Las páginas siguientes describen los aspectos técnicos, compositivos y funcionales de la intervención.
SUMMARY

The Monastery of Santa Maria, Spanish National Monument since June 1931, grew up between the 10th and the 18th centuries becoming a prominent administrative and spiritual centre. Every historic addition to the complex, though clearly reflecting its era, was conceived preserving the former space scheme.

Things changed in the 19th century: Laws forced the monks to leave the abbey behind, while subsoil humidity began to attack limestone reducing its endurance. Even though the situation drove the monastery near to ruin and caused irretrievable damage to art works, the church kept the daily worship.

In 1984 the Regional Administration decided to broach a wide restoration of the monument. Works as well as its simultaneous research and documentation process, were developed during 6 years with a close cooperation among specialists. Thus, a new phase in the building's life was concluded. Unknown clues were afforded about his old space order (that was clarified) and a great attention was payed to the relationship between old and new elements.

Next pages describes technical, compositional and functional aspects of the intervention.

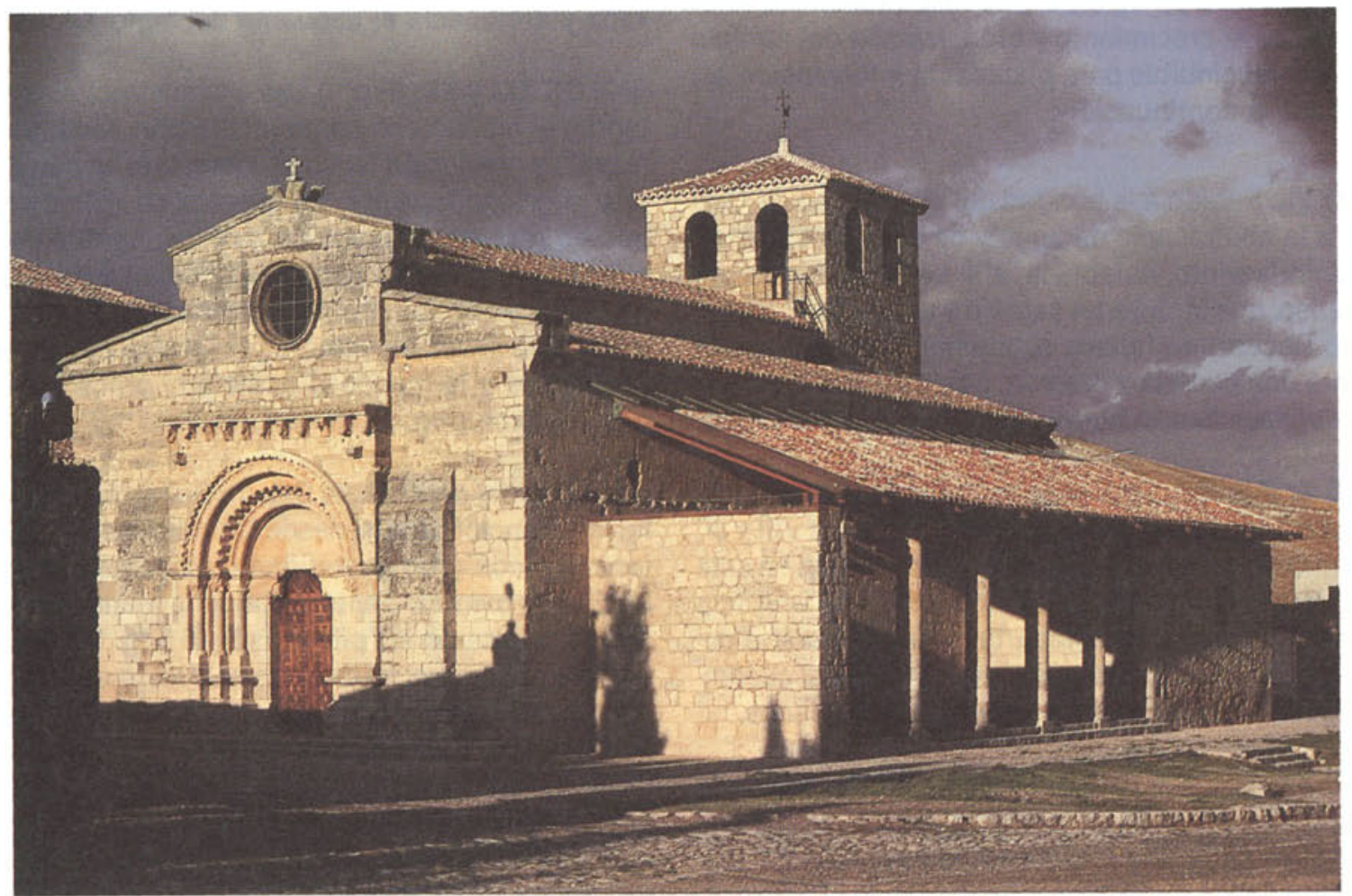

La iglesia restaurada desde el SO. 
El conjunto del monasterio de Santa María, Monumento Nacional desde junio de 1931 , se levanta en el limite septentrional del antiguo recinto medieval de Wamba y representa una pequeña muestra del importante complejo monástico que creció entre los siglos X y XVIII sobre las estancias reales de un hábitat visigodo con origen tardorromano.

En 1984, el deterioro progresivo que sufria la abadia no podía ser contenido con el mantenimiento derivado del uso de su iglesia. Casi todas sus edificaciones históricas habian desaparecido, y las que se conservaban sufrían agudos daños estructurales, constructivos y artísticos, manifestando la tradicional escasez de recursos para la conservación del Patrimonio Histórico español.

En aquel momento, la Junta de Castilla y León decidió su rehabilitación, encuadrándola en un programa de restauración de edificios mozárabes que ya contemplaba los casos de San Miguel de Escalada y San $\mathrm{Ce}$ brián de Mazote.

\section{Antecedentes históricos. Formación del Monasterio}

Se inició una investigación basada en un cuidadoso levantamiento de planos, en la consulta de bibliografia, archivos y libros de fábrica, en el estudio de las restauraciones recientes y en el análisis geométrico de las estructuras visibles. Sus resultados, que arrojaron sobre el crecimiento y organización del edificio la luz imprescindible para plantear la intervención, se sintetizan a continuación:

SIGLO VII: Debido a la bondad del microclima de Gertici y a la abundancia de agua y de caza en su entorno, Chindasvinto establece alli una residencia de descanso, que incluye un palacio y una iglesia. Su heredero Recesvinto fallece súbitamente en el poblado durante una cacería y Wamba, noble visigodo, es elegido sucesor dando nuevo hodónimo a la localidad.

SIGLO X: (Fig. 2.a) Tras el abandono del poblado y la desaparición de su caserío durante los siglos VIII y IX, Frunimio obispo dimisionario de León, edifica en esta zona de repoblación un pequeño convento con una iglesia mozárabe muy compartimentada y masiva cuyas proporciones, basadas en la geometría del cuadrado, siguen la rectitud de los trazados asturianos.

SIGLO XII: (Fig. 2.b) El asentamiento en Wamba de la Orden de San Juan de Jerusalén y la fundación de un hospital de peregrinos favorecen la aparición de nuevas estancias al norte de la iglesia y de un claustro en torno a la prolongación septentrional del eje del tran- septo. Quizás se construyera en esta época el campanario que coronó el crucero hasta principios del siglo XX.

SIGLO XIII: (Fig. 2.c) Se reemplazan las abovedadas naves mozárabes al oeste del transepto por una esbelta y unitaria sala románica que, cubierta por estructura de madera, se integra hábilmente en el conjunto gracias al buen uso de la geometría y a la comprensión del esquema espacial mozárabe.

SIGLOS XIII al XVIII: Según indican las fuentes consultadas, en este periodo el monasterio creció ocupando hacia oriente parte de la actual Plaza de España y hacia occidente un sector de la parcela contigua. No ha sido posible contrastar la primera información debido a la ausencia en esa zona de estructuras históricas visibles.

SIGLO XVIII: (Fig. 2.d) Con la transformación de la Orden de San Juan de Jerusalén en la de Malta, la pujante Encomienda de Wamba adosa al sur de la iglesia un atrio y una sacristía. Se abren mayores ventanales dotados de vitrales (dañando de forma irreversible la valiosa pintura mural del siglo $X$ de la cabecera, Fig. 15.a) y se instala a los pies del templo un coro cuyos mechinales reducen drásticamente la capacidad portante de los soportes 2 y 9 (Figs. 1 y $8 . a$ ).

Las intervenciones llevadas a cabo sobre el edificio hasta ese instante habian logrado crear un conjunto que, reflejando en cada pieza la concepción espacial del momento histórico que lo había producido, conservaba y enriquecía el esquema del siglo XII.

SIGLOS XIX y XX: (Fig. 1) Las exclaustraciones desintegran el monasterio como institución, facilitando su expolio y disolución física al convertirlo en cantera barata (afortunadamente, los museos de Valladolid han podido rescatar algunos de sus fragmentos como el altar mayor y ciertos capiteles). Surgen edificaciones parásitas en el claustro, las cubiertas hacen agua y co. mienzan a ceder, se entarima la iglesia, se ciegan los ventanales y la humedad acelera el proceso de descomposición (Fig. 3).

A lo largo del siglo XX, la D.G. de Bellas Artes desarroIló intervenciones que, desde los criterios vigentes entonces y con gran austeridad de medios aunque sin unidad de planteamiento, evitaron la muerte de la iglesia: se reforzaron las pilastras 5 y 6 (Fig. 1) y la cimentación del crucero; se desenterró y restauró la portada occidental reponiendo los elementos desaparecidos; se reemplazó el campanario por otro más ligero; se sustituyeron las cubiertas del templo y de sus estancias anejas excepto la de la sacristía y se corrigieron desagües y solados en los espacios públicos colindantes. No era posible abarcar más con menos, pero aún quedaban pendientes graves problemas. 


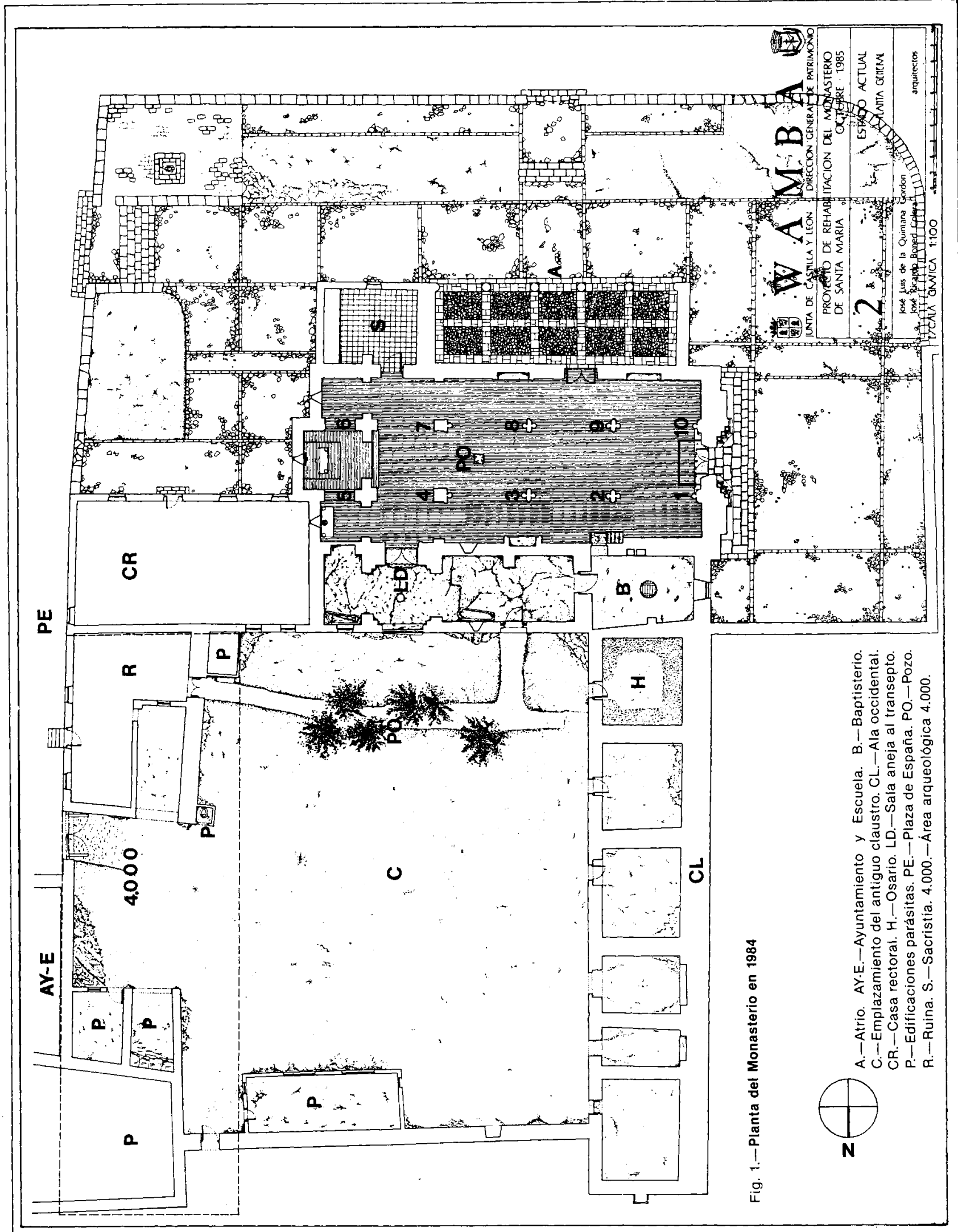




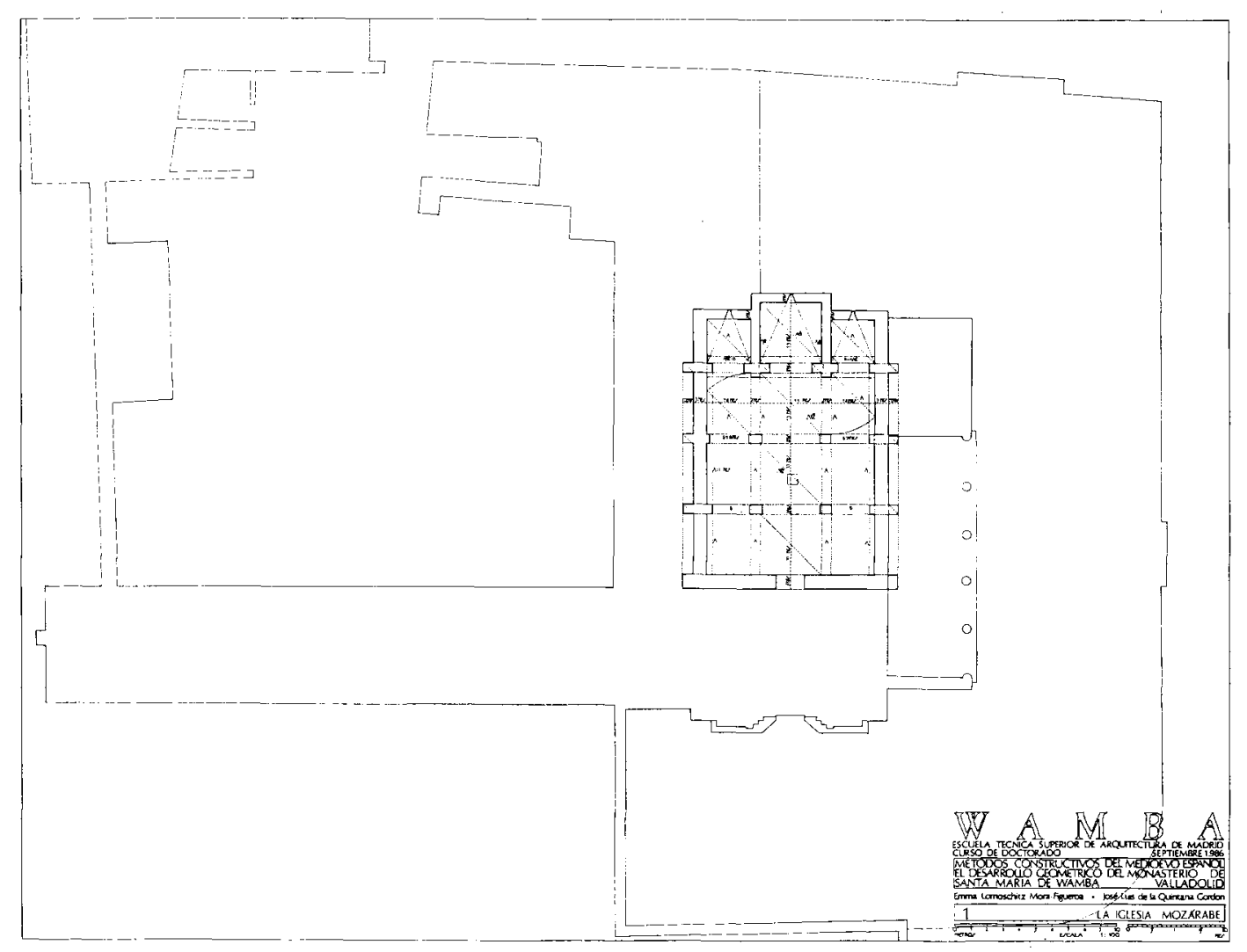

Fig. 2.a.-SIGLO X: La iglesia mozárabe sobre la silueta del conjunto en 1984. La nave central se forma por la repetición a lo largo del eje Este-Oeste, de la planta de la capilla mayor, cuadrada de 11 pies mozárabes de lado con muros de 2 pies de espesor. Las naves laterales resultan de la adición de estancias con planta 11 X 11/ $\sqrt{2}$ pies. (1 pie mozárabe $=0,33 \mathrm{~m}$ ).

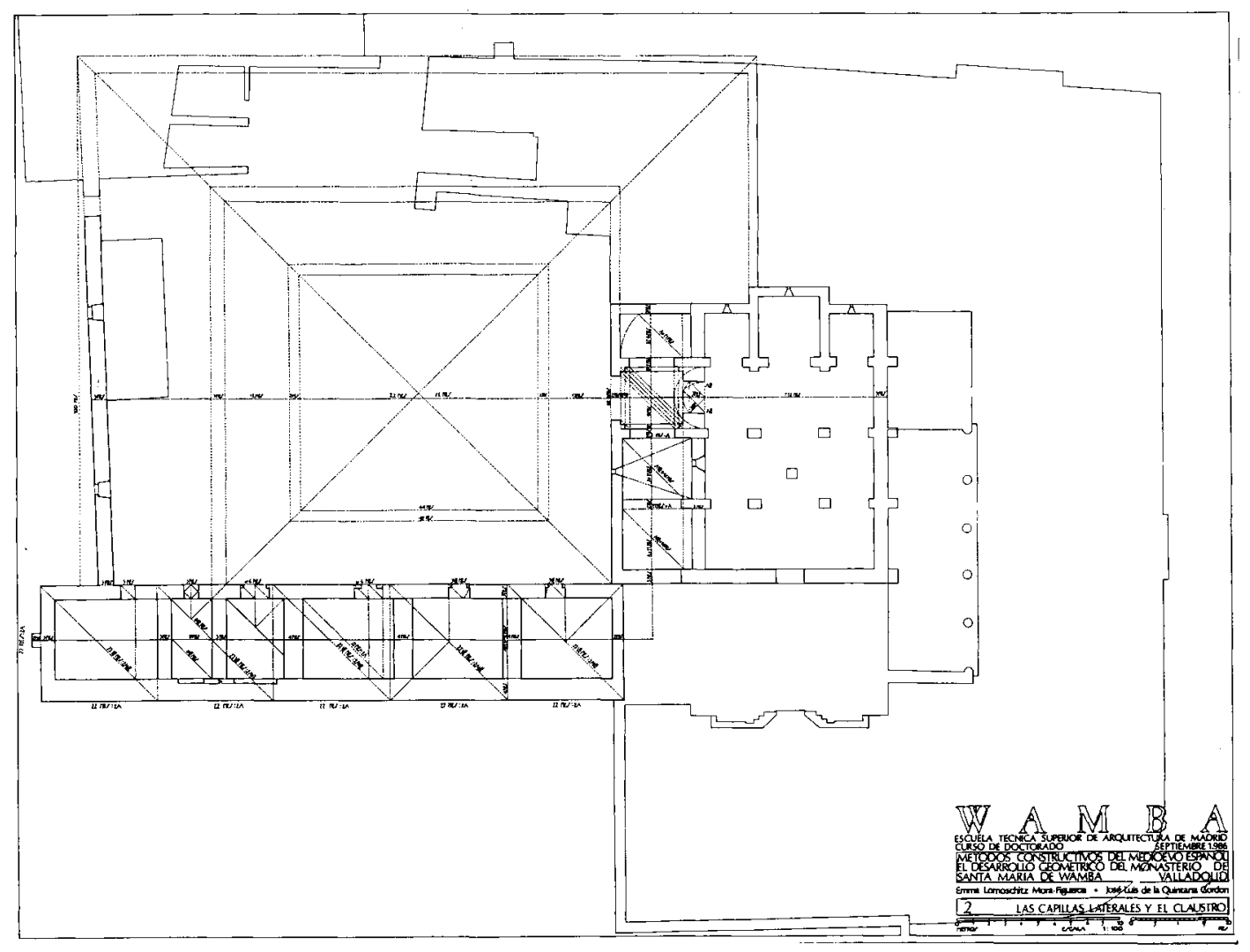

Fig. 2.b.-SIGLO XII: Surge el claustro románico. El módulo es el cuadrado de $11 \times 11$ pies, aunque con irregularidades en el trazado. Los enjarjes de muro visibles evocan un espacio libre de $44 \times 44$ (4x11) pies de lado, rodeado por una galería de 11 pies de anchura. Los muros y el zócalo del peristilo son de 2 pies de espesor. 


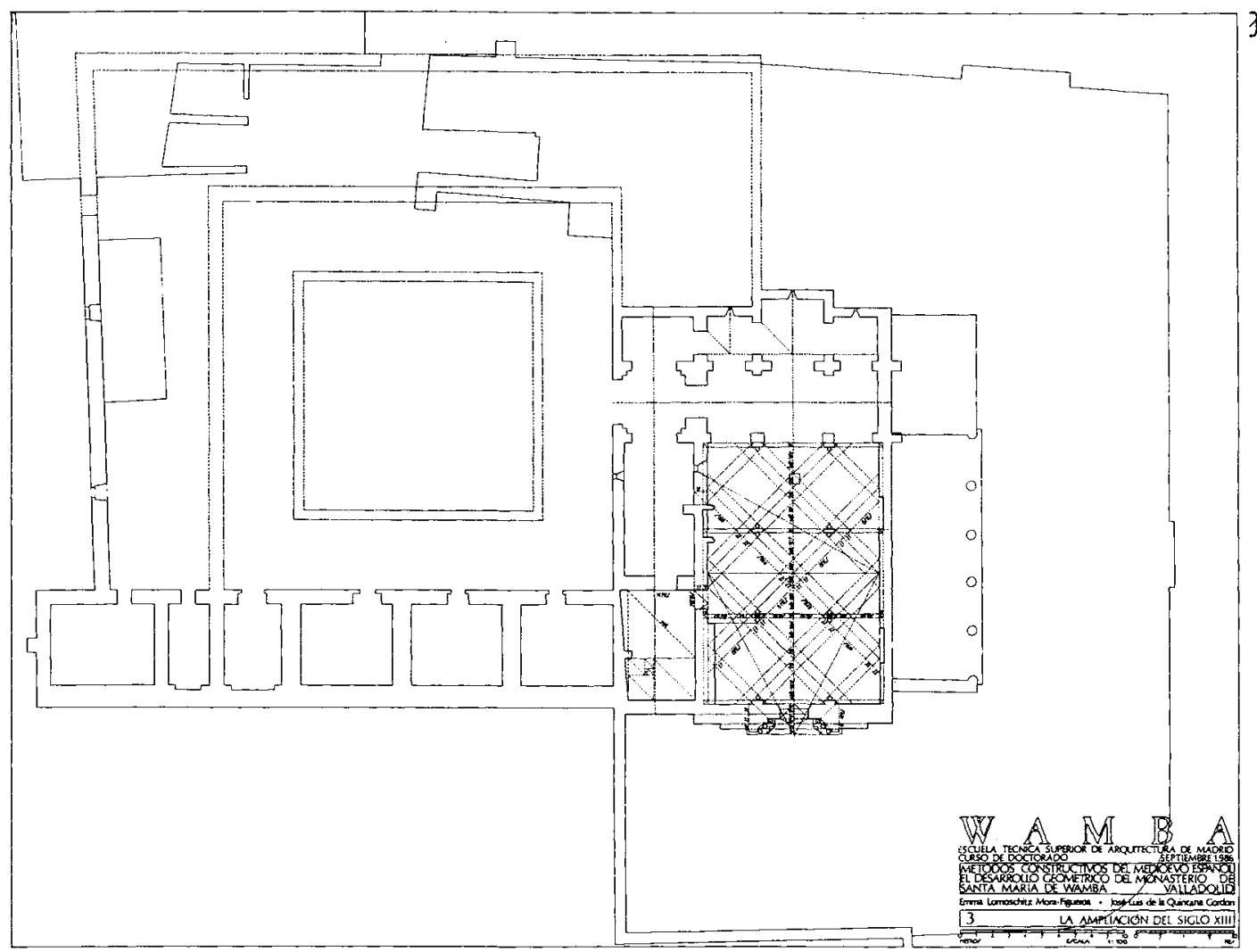

Fig. 2.c.-SIGLO XIII: Se amplia la iglesia con una sala de proporción de planta $3 \times 2$. Sus soportes están en las intersecciones de una malla que genera cuadrados de 2 y 8 pies carolingios de lado, girada $45^{\circ}$ respecto al eje E-O 1 pie carolingio $=0,32 \mathrm{~m}$ ). Los paramentos laterales coinciden con las intersecciones de la malla.

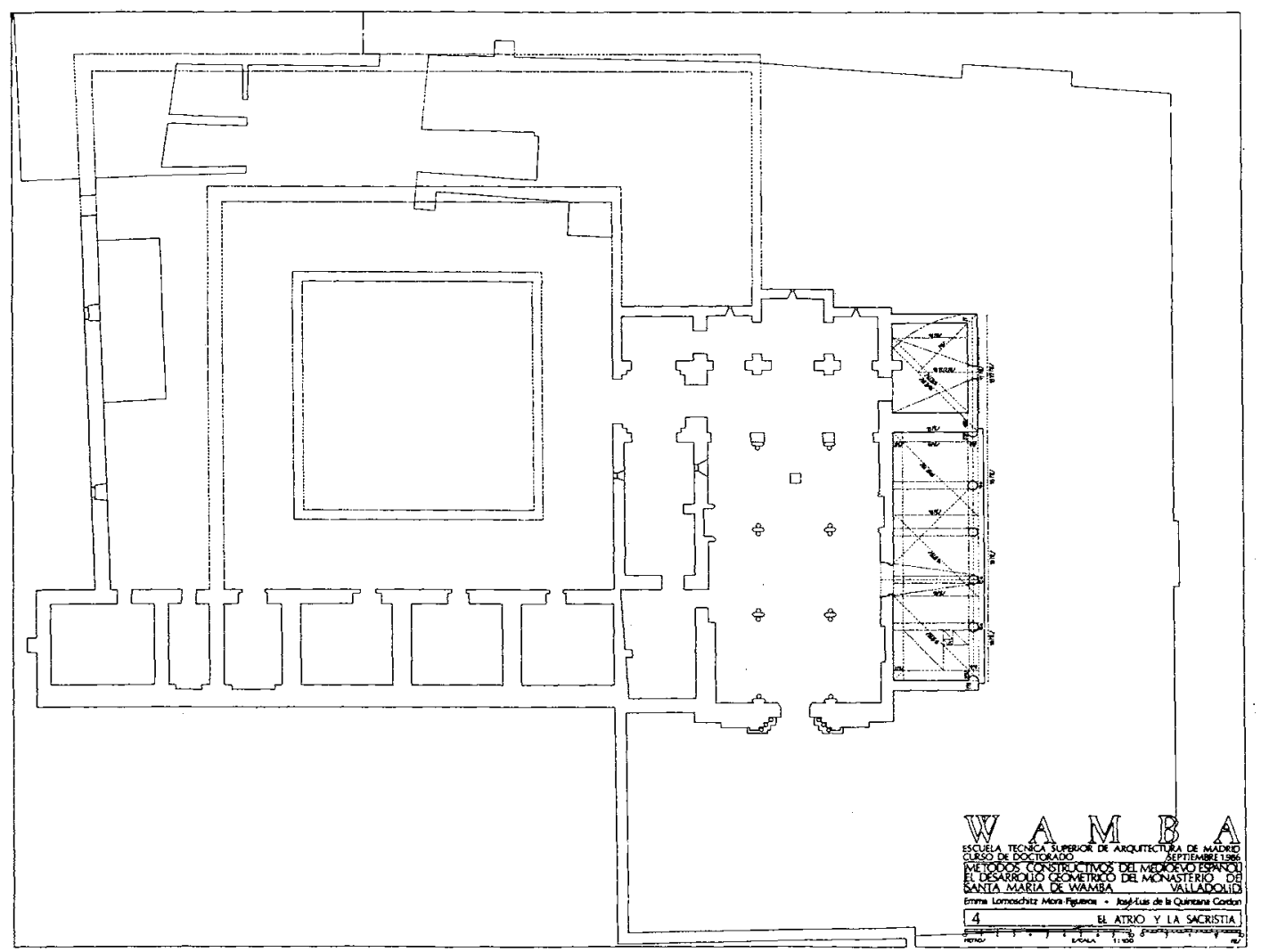

Fig. 2.d.-SIGLO XVIII: La planta del atrio se forma por adición de 3 cuadrados de 21 pies castellanos de lado (1 pie castellano $=0,28 \mathrm{~m}$ ). La planta de la sacristia es de $21 \times 21 \sqrt{ } 2$ pies. 

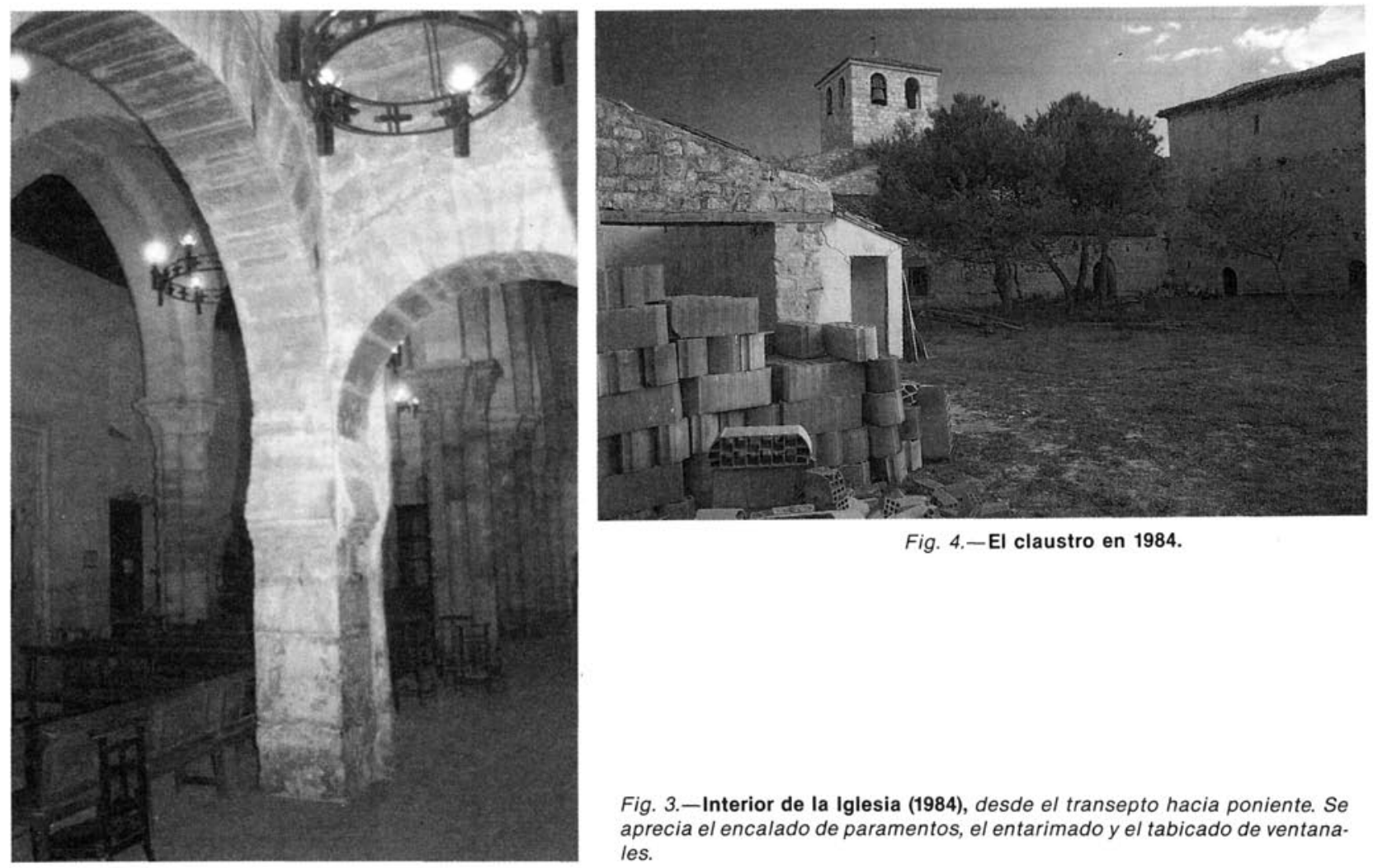

Fig. 4.-El claustro en 1984.

Fig. 3.-Interior de la Iglesia (1984), desde el transepto hacia poniente. Se aprecia el encalado de paramentos, el entarimado y el tabicado de ventanales.
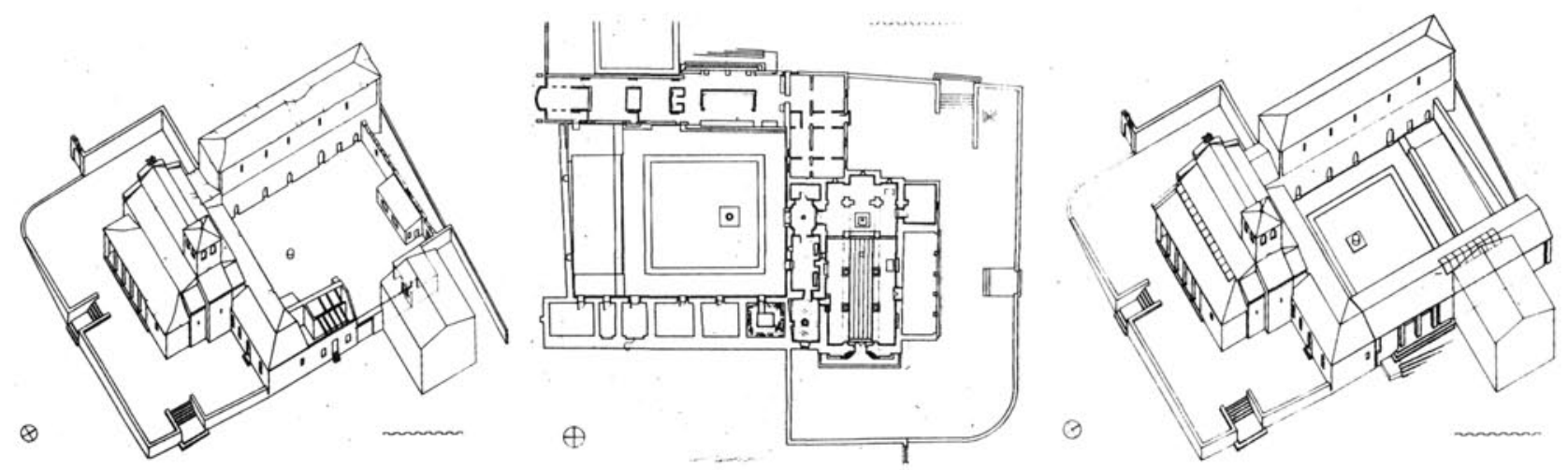

Fig. 5.-Isometria del Monasterio en 1984. Fig. 6.-Planta del proyecto de restauración. Fig. 7.-Isometria del proyecto de restauración.

\section{Antecedentes patológicos: estado del Monasterio en 1984}

Las hipótesis de carga que para supuestas condicio. nes óptimas de la piedra se realizaron en la fase de documentación, arrojaron unos valores de compresión en cada soporte de $127 \mathrm{t}$, lo que indicaba un buen coeficiente de trabajo de unos $50 \mathrm{~kg} / \mathrm{cm}^{2}$ en cada fuste. Esto corroboraba que en origen la iglesia estaba bien equilibrada gracias a la simetría de su planta, al considerable espesor de sus muros y a la racional disposición de los soportes románicos interiores que, pese a su atrevida sección compuesta, podian soportar el gran peso trasmitido por los arcos formeros.

Sin embargo, las corrientes subterráneas del empla- Consejo Superior (existen dos pozozos en los ejes de iglesia y Licencia Creative Commons 3.0 España (by-nc) claustro, Fig. 1) y la naturaleza de un suelo arcilloso que sólo en seco alcanza buena resistencia a la com. presión, habían provocado la desestabilización de la cimentación (desplazamiento hacia el oeste de las zapatas del pórtico 1-2-3-4 con grietas en arco 1-2 y asentamiento diferencial del pilar 9 con fisuraciones en arco 8-9 (Fig. 1), así como el irregular depósito superficial de las aguas colgadas que se evaporaban tras ascender capilarmente más de $4 \mathrm{~m}$ por las fábricas (durante el invierno de 1985 algunos sectores de muro alcanzaron el $100 \%$ de humedad relativa, apareciendo goteos superficiales espontáneos). Esta situación crónica, unida a la escasa ventilación, había causado daños irreversibles en la obra mueble y en la decoración mural (Fig. 15.a). 


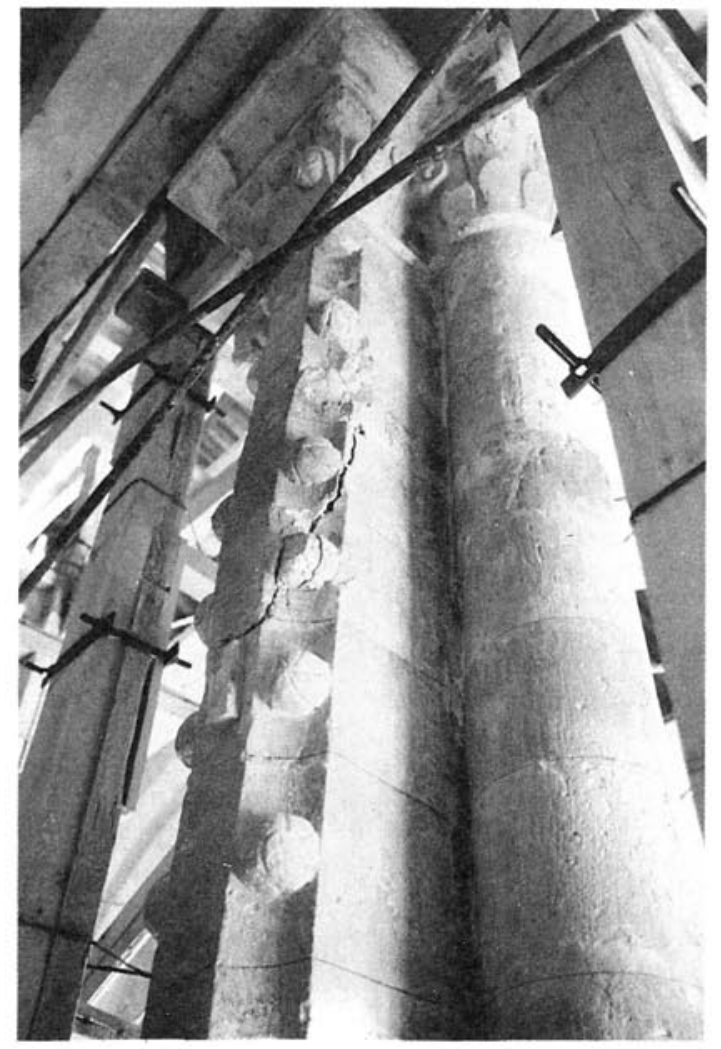

Fig. 8.a.-El soporte "2" en 1984.

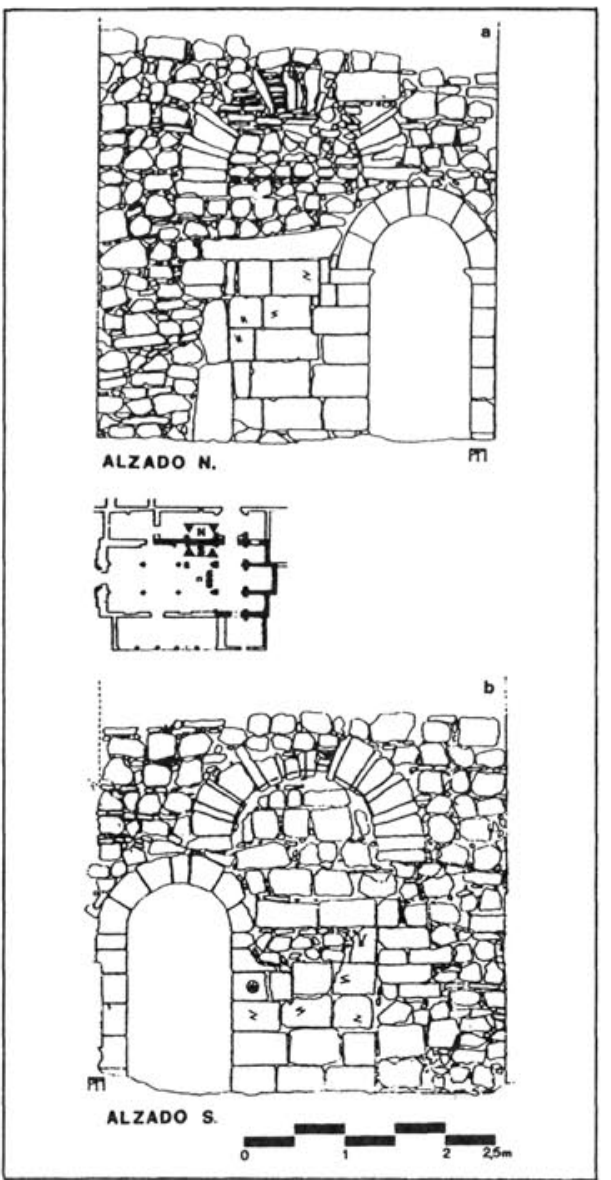

(c) Consejo Superior de Investigaciones Científicas Licencia Creative Commons 3.0 España (by-nc)

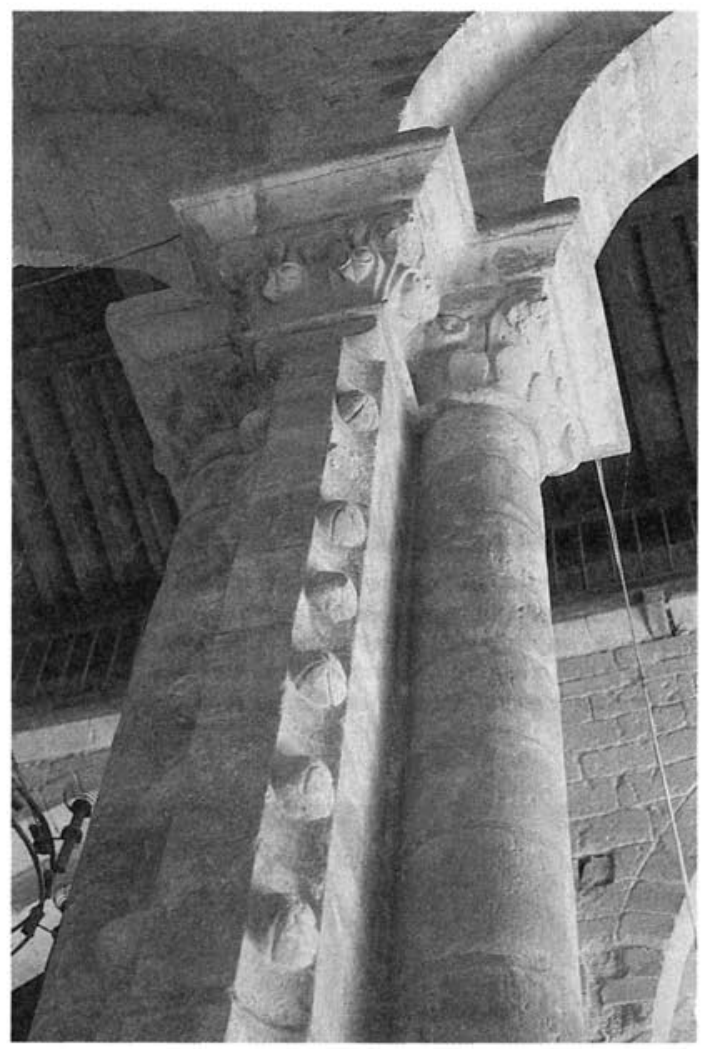

Fig. 8.b.-El soporte "2" tras su consolidación.

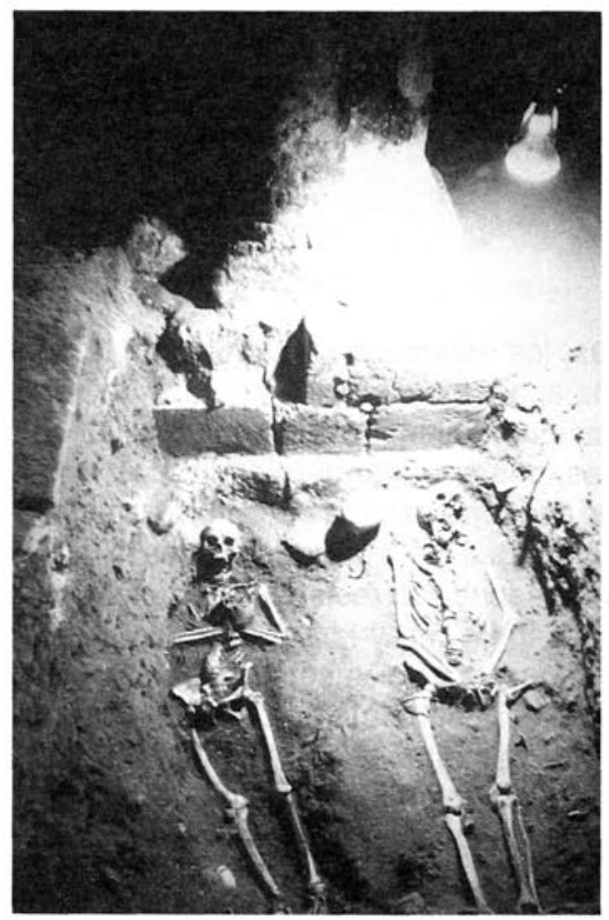

Fig. 9.b.-Excavaciones en la Iglesia: Enterramien. tos junto al soporte " 3 ". Hallazgo de las basas me. dievales y de la cota del solado original.

Fig. 9.a.-Puerta y huellas de otras descubiertas en el muro N. de la iglesia. (Levantamiento: Pedro Matesanz, arqueólogo).
http://informesdelaconstruccion.revistas.csic.es 


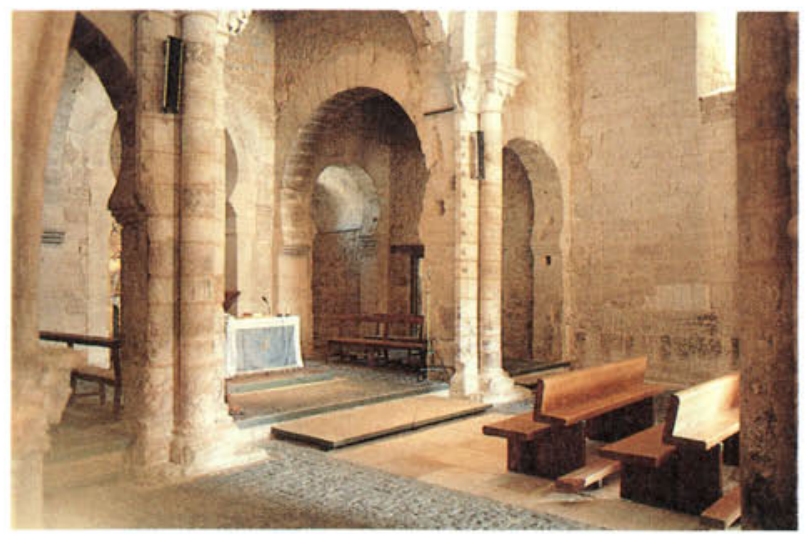

Fig. 10.-El transepto desde la nave románica restaurada. El ara del altar ocupa el centro geométrico del crucero, bajo la bóveda mozá. rabe más elevada y se ilumina cenitalmente. El cambio de cota se resolvió con mesetas "flotantes" de garbancillo lavado. El pavimento de la nave central recoge las piezas recuperadas del solado me. dieval.

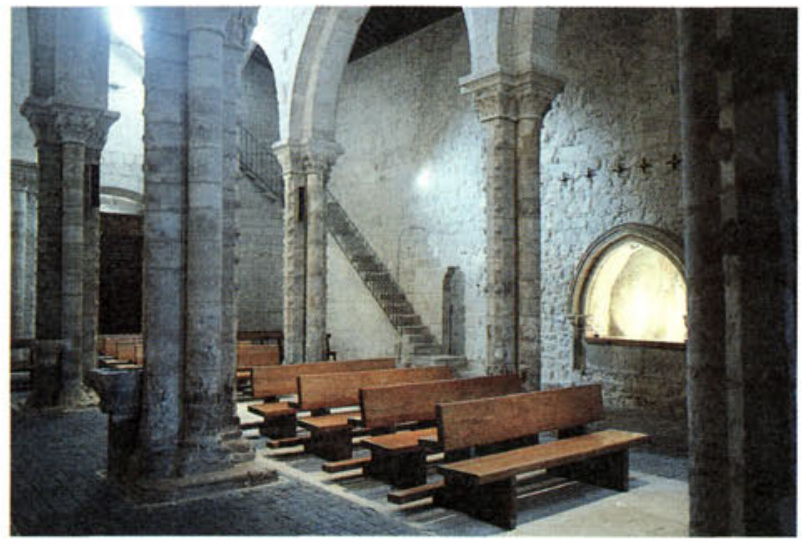

Fig. 12.-Las naves románicas restauradas, hacia el NO.

Además, los estados de histéresis de la piedra debidos a la aparición de ciclos alternos de hidratación y desecación, habian provocado la formación de sales solubles, posteriormente cristalizadas, con la consiguiente descomposición por rotura de la piedra de algunos soportes. Esto, que justificaba la teórica reducción de la capacidad resistente en zonas plastificadas hasta los $10 \mathrm{~kg} / \mathrm{cm}^{2}$ y la aparición de estados de fle. xión compuesta en elementos no preparados para ello, junto con el debilitamiento causado en algunos pilares por los mechinales abiertos durante el siglo XVIII, había producido en los números 2 y 9 (Fig. 1) roturas con riesgo de aplastamiento y de evolución imprevisible (Fig. 8.a).

Las bóvedas de las salas LD, $\mathrm{H}$ y CL (Fig. 1), mostraban indicios de sobrecarga. La primera, de lajas de piedra y argamasa, estaba apuntalada por una columna caliza semidescompuesta. Todas sufrian flechas y desplomes debidos a depósitos en su trasdós y a la entrada de agua a través de los tejados. (c) Consejo Superior de Investigaciones Científicas Licencia Creative Commons 3.0 España (by-nc)

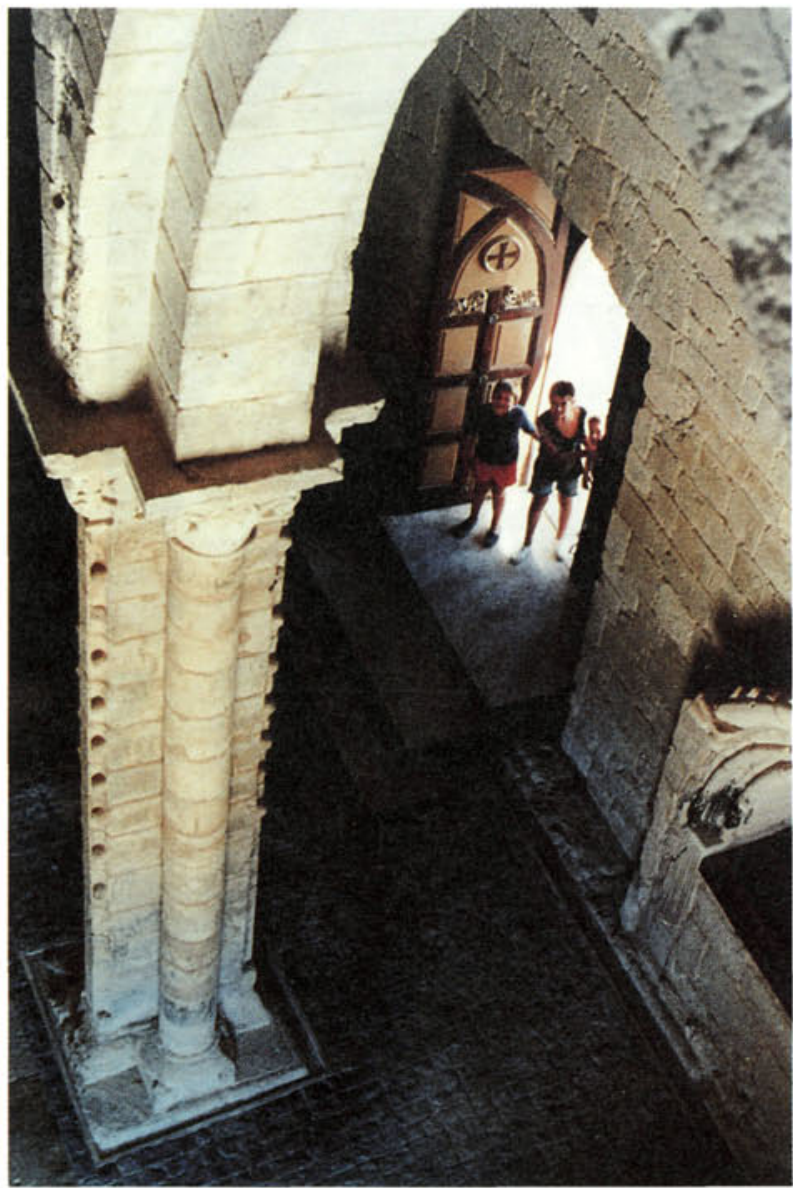

Fig. 11.-Detalle de la pavimentación. El rebaje de su nivel forzó a resolver el acceso con mesetas "flotantes" de garbancillo lavado, sobre el zócalo románico que discurre bajo ellas. El encuentro en. tre nuevo pavimento y elementos medievales consiste en una junta rebajada del mismo material.

Las cubiertas de la iglesia, recientemente sustituidas, estaban resueltas mediante cerchas de madera, con tirantes metálicos que evitaban los empujes horizontales en cabeza de muro. Las fábricas no mostraban deterioro por el fracaso de elementos portantes de cubierta, aunque el resto de los tejados del monasterio daba signos de colapso y riesgo de ruina, por pudrición y ataques de xilófagos.

\section{Antecedentes funcionales: estado en 1984}

Sólo la iglesia matenía su actividad en la penumbra pese a la degradación de su estructura y de su patrimonio mueble. El orden espacial del monasterio se había perdido al desmontarse piedra a piedra para levantar viviendas, graneros y hasta el Ayuntamiento. Además de la iglesia, sólo quedaban en pie el cerramiento norte del conjunto, posible fragmento de la fortificación medieval de Wamba, y el ala poniente del claustro que, coronada por unos corrales arruinados http://informesdelaconstruccion.revistas.csic.es 


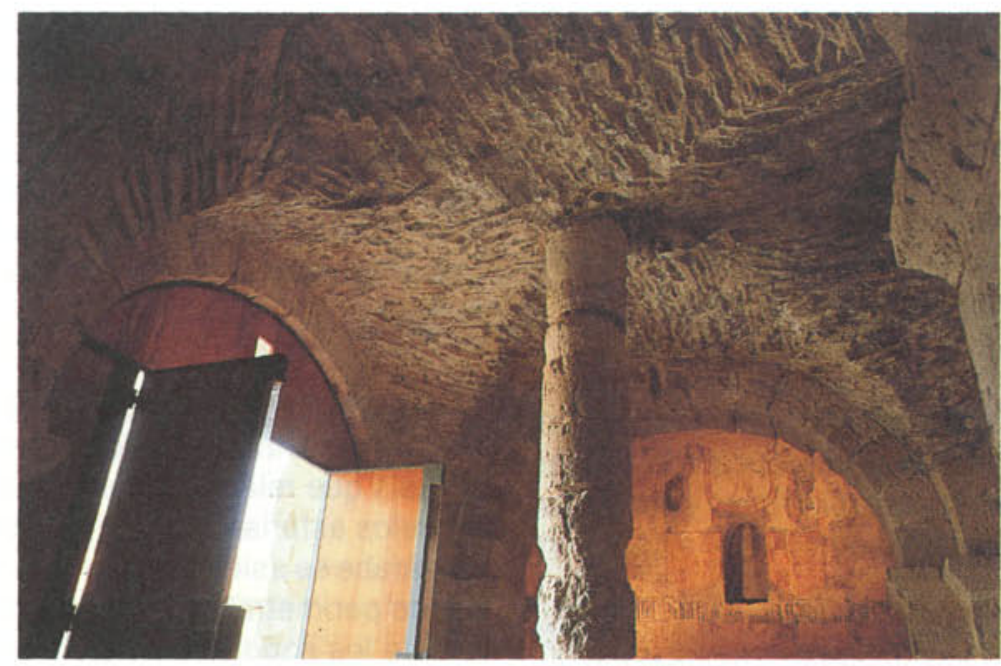

Fig. 13. - Sala LD, bóveda consolidada. Se mantuvo la columna de apuntalamiento del S. XVII. A la izquierda carpinterias de salida al claustro. Al fondo, pintura mural del S. XV, restaurada.

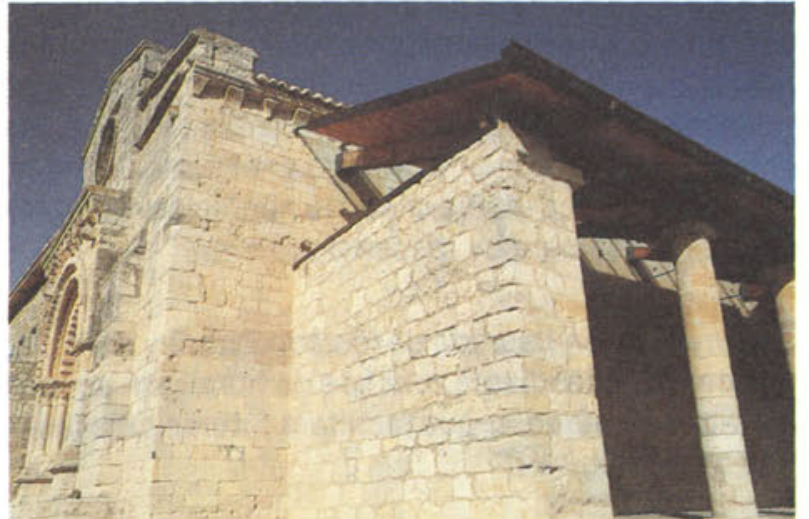

Fig. 14.a.-Nueva cubierta del atrio, desde el exterior.

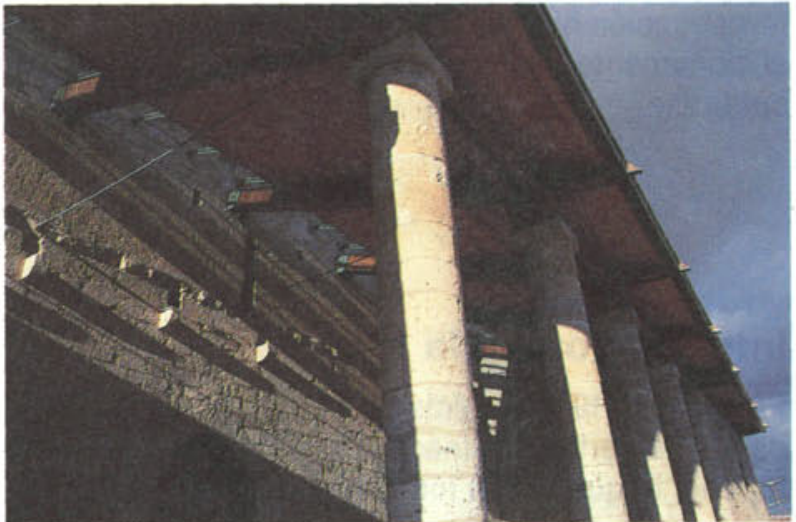

Fig. 14.b. - Nueva cubierta del atrio: Vista del interior. de propiedad privada, contenía el famoso y destartalado "Osario" (Fig. 17.a) y cinco salas vacias. Las estancias sin uso adosadas al flanco norte de la iglesia, enmarcaban por el sur el antiguo claustro transformado en huerta, garaje y lugar de almacenamiento (Figs. $1,4$ y 5$)$.

En aquel momento, pese a que la cercanía de Valladolid habia evitado la emigración masiva y el nivel de población se mantenia estable, Wamba adolecía de ciertos servicios básicos: la escuela contigua (Fig. 1) carecía de biblioteca y los únicos locales de reunión en el pueblo eran el Ayuntamiento y los bares.

\section{Conclusiones de la documentación}

La perspectiva del problema confirió a la operación que se planeaba la dimensión de ser un eslabón más en la cadena de transformaciones históricas del recinto y movió a asumir la norma conductora de todas las in- tervenciones documentadas: el análisis del esquema espacial generador de la abadia, para aplicar sobre él la nueva actuación desde planteamientos contemporáneos, pero de forma integrada con las estructuras preexistentes.

Sin embargo, el enfoque era inédito: nunca habia sido preciso regenerar el monasterio tras su deshaucio. Por ello, la actuación que debía ser global, afectaria a las piezas conservadas, crearía otras y respondería a un planteamiento unitario en diseño y soluciones constructivas para imprimir a la obra nueva un carácter identificable.

Por primera vez en Wamba se valoraría el substrato arqueológico que no podia dañarse y se buscaria el equilibrio entre el mantenimiento de las huellas del paso del tiempo y una restauración que debería ser didáctica y explicativa de la vida del monumento. Además, se prestaria especial atención a la colaboración estrecha entre especialistas, y a la delicada relación de las estructuras nuevas con las históricas. 
Objetivos del proyecto de rehabilitación (Figs. 6 y 7 )

Fueron los siguientes:

Consolidación de las estructuras fracturadas, saneado de las humedades y restauración de los bienes de interés cultural aplicando técnicas de mínimo efecto traumático.

Clarificación del esquema espacial perdido, eliminando construcciones parásitas e introduciendo nuevas piezas que manifestaran las articulaciones y escala del antiguo conjunto edificado y permitieran la comprensión de su desarrollo.

Mantenimiento de los usos vigentes y asignación, en su caso, de otros nuevos que garantizasen la conservación del monasterio.

Investigación histórica, arqueológica y artística sobre el monumento, elaborando inventarios de pintura y escultura.

\section{Intervención en la Iglesia}

En enero de 1988 se iniciaron los trabajos desmontando las cubiertas arruinadas de atrio, sacristía y baptisterio, lo que arrojó los resultados siguientes:

1) Descubrimiento tras el tejado de atrio y sacristía, de un sector de la fachada románica meridional con valiosas huellas de las diferentes fases de construcción del templo. Se liberaron los ventanales del siglo XVIII ocultos por la cámara de cubierta.

2) Hallazgo tras la demolición del falso techo de escayola de la sacristía, de diversos elementos decorativos de yeso pertenecientes al techo original.

3) Aparición de varios canecillos románicos enterrados bajo la cubierta del baptisterio.

Simultáneamente se consolidaron los soportes 2 y 3 (Figs. 1 y 8.b) y el encuentro del pórtico 1-2-3-4 (Fig. 1) con la fachada poniente, mediante inyecciones de lechada de cemento con presión en boca de toma de 1,5 $\mathrm{kg} / \mathrm{cm}^{2}$, que se armaron con redondos corrugados $\varnothing 16$ de acero AEH-400. Los taladros de $36 \mathrm{~mm}$ de diámetro se efectuaron ortogonalmente cada $100 \mathrm{~cm}$ a $\mathrm{lo}$ largo de los fustes, mediante coronas de diamante con alta velocidad de giro sin percusión para reducir al máximo las vibraciones en la estructura debilitada. Los fragmentos sueltos se fijaron con resinas epoxídicas.
En las naves, tras confirmar arqueólogos y restauradores la inexistencia de decoración mural a excepción de la conocida en cabecera y nicho del muro norte, se eliminaron las empapadas capas de cal. Asi se disminuyó el nivel de humedad ambiental y se recuperaron las trazas de elementos desconocidos como arcos y pasos tabicados que ampliaron el conocimiento del templo (Fig. 9.a).

La excavación arqueólogica, que siguió el sistema Harris, alcanzó niveles tardorromanos e incidió en las hipótesis que relacionan el trazado de Wamba con los modelos asturianos. Además, confirmó que el edificio mozárabe se asienta sobre otro anterior, descubrió un banco perimetral en la nave románica y liberó las basas de los soportes del S. XIII (bajo varios niveles de enterramientos de los S. XVII y XVIII), definiendo la cota del solado original (Fig. 9.b). Esto no fue posible en cabecera y transepto por la aparición de apuntalamientos de hormigón en masa para refuerzo de la cimentación del crucero, que no permitieron hallar vestigios de iconostasis o relaciones estructurales entre pilares. A niveles más profundos y con una potencia de $1,10 \mathrm{~m}$, los enterramientos habian destruido gran parte de los niveles alto y pleno medievales. No aparecieron ajuares aunque sí restos muy dispersos.

La cimentación fisurada de los soportes 3 y 4 (Fig. 1), se consolidó mediante zunchos de hormigón armado sin vigas de atado, lo que facilitará futuras excavaciones arqueológicas.

La humedad reptante se trató por el sistema de electroósmosis-fóresis, colocando electrodos de cobre conectados a tierra e inyectando sales y líquido de fóresis en la base de los muros afectados, para crear en todo su espesor una barrera impermeable por colmatación salina irreversible de los capilares. El proceso fue lento, evitándose que una desecación repentina produjera fisuraciones inesperadas.

El nuevo pavimento del templo tiene distintos niveles en las zonas mozárabe y románica (Fig. 10), ayudando a diferenciarlas y facilitando el seguimiento de los actos litúrgicos. Se resolvió con una cuadrícula de adoquín de piedra de Calatorao de $10 \times 10 \times 10 \mathrm{~cm}^{3}$ delimitada por encintados de caliza de Campaspero, ejecutándose en garbancillo lavado los encuentros con los elementos medievales. Sobre su fondo neutro des. tacan las basas recuperadas de los soportes (Fig. 11) y los restos de solados y lápidas, en sus emplazamien. tos primitivos. Las naves románicas han recobrado así su esbeltez. En la sala LD (Fig. 1), tras la consolidación de su bóveda (Fig. 13), así como en baptisterio y sacristía, se colocó un solado de barro cocido (utilizado en origen en esas zonas), modulado a $30 \times 30 \mathrm{~cm}$, con la misma solución de bordillos y encuentros que en el templo. 


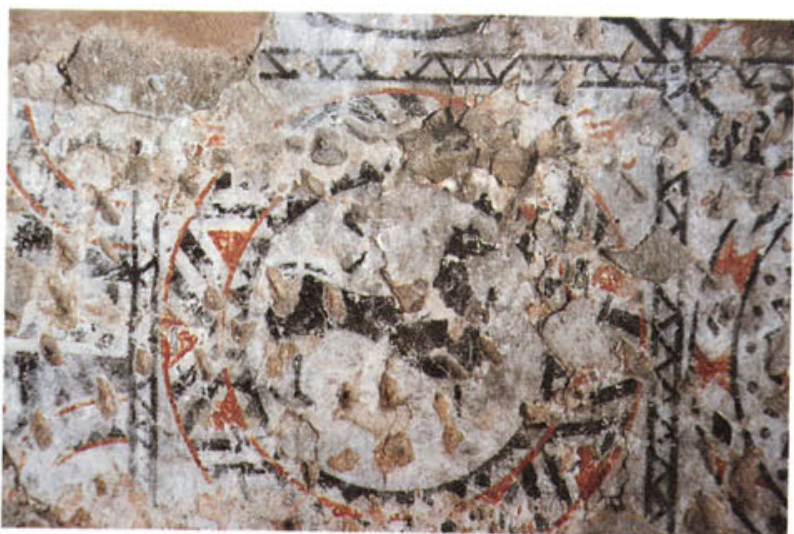

Fig. 15.a.-Pintura mural del S. X en Capilla Mayor (1984).

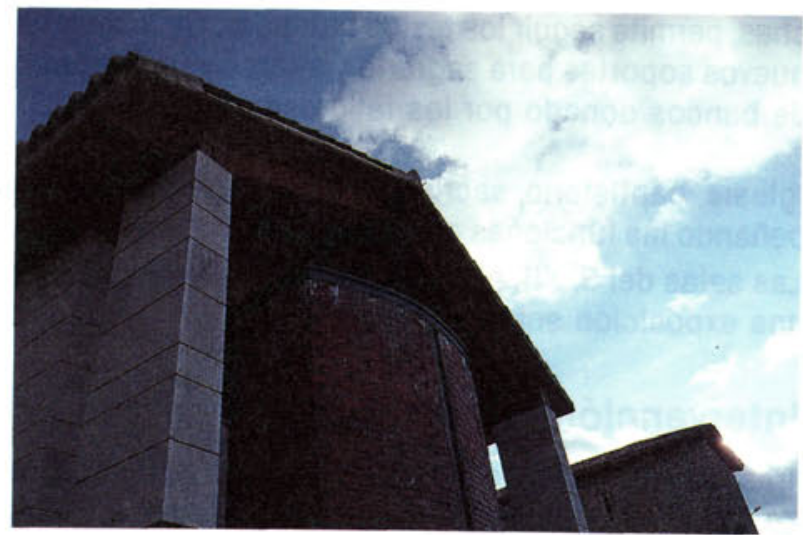

Fig. 16.a.-Cabecera (inacabada) del nuevo Pabellón Oriental.

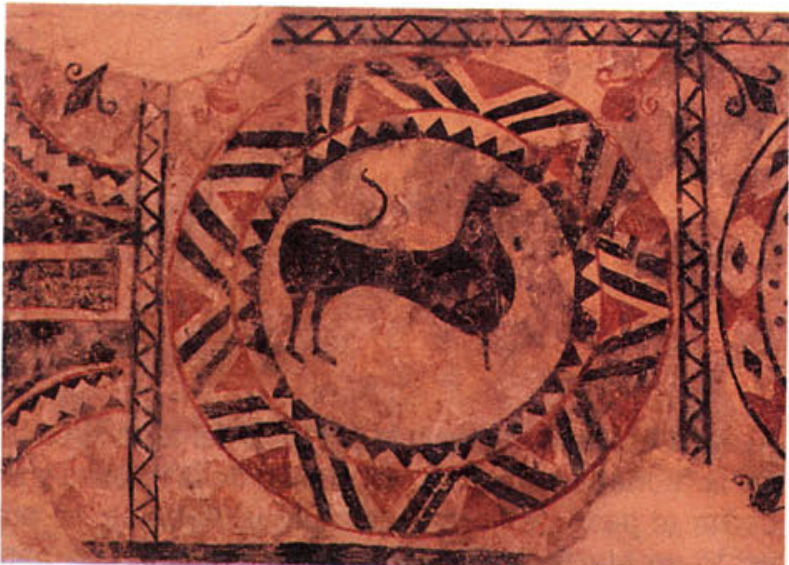

Fig. 15.b.-Pintura mural del S. $\mathbf{X}$ en Capilla Mayor, restaurada.

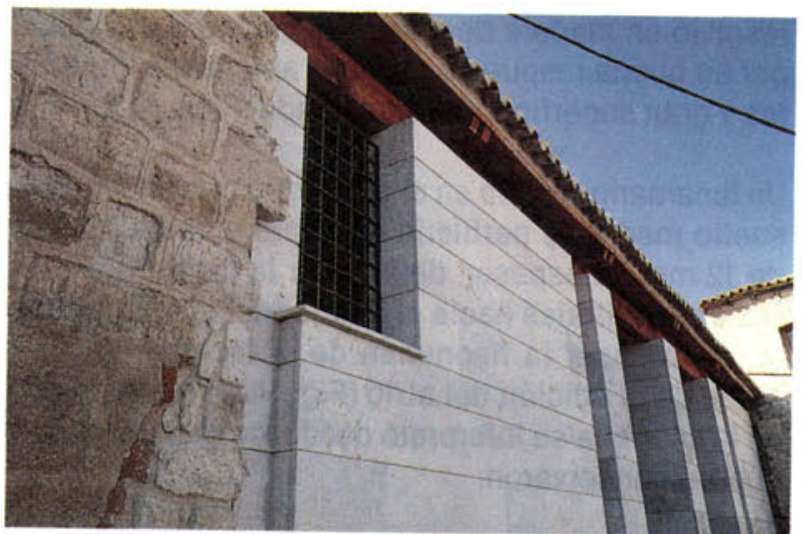

Fig. 16.b. - Fachada (inacabada) a Plaza de España del nuevo Pabe. llón Oriental y encuentro con la casa rectoral.

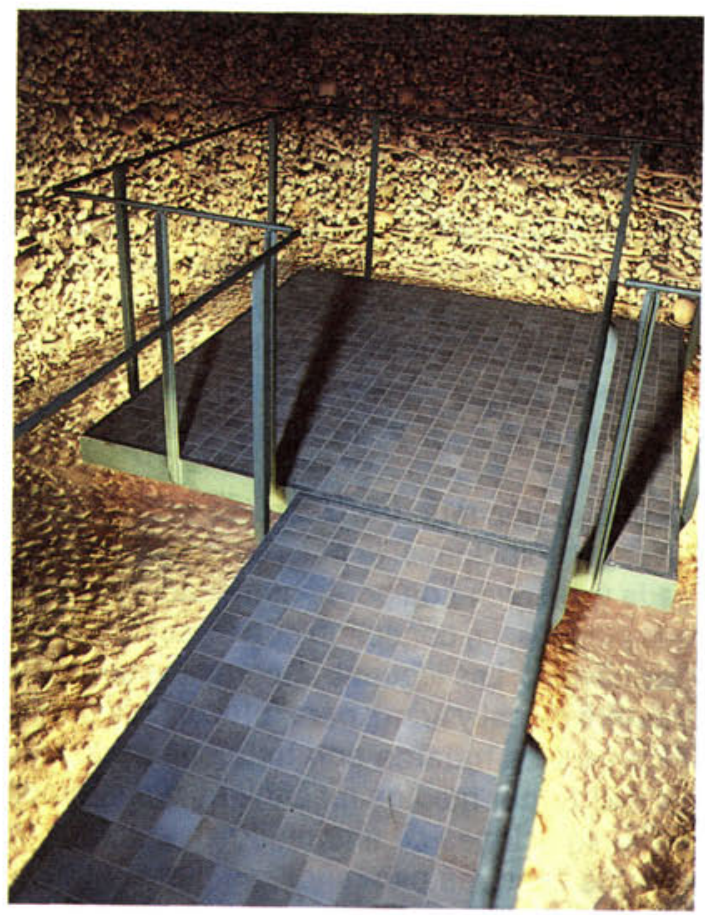

Fig. 17.b. - El Osario restaurado. Una plataforma "flotante" bajo la cual surge luz, permite su visita y protección. 
Al ser preciso reconstruir la cubierta del atrio sin ocultar la fachada románica meridional de la iglesia, y sin cerrar el paso de la luz hacia los ventanales, se pro. yectó un plano inclinado con el menor número posible de anclajes (perforaciones armadas idénticas a las realizadas en soportes interiores, con ángulo de ata. que de $45^{\circ}$ respecto del paramento). La estructura se resolvió en madera de pino Oregón con pares dobles por su buena respuesta a flecha ante luces importantes y gran superficie de entrevigado (Figs. 14.a y 14.b).

Un lucernario corrido en el encuentro cubierta-muro resuelto mediante perfilería de acero y lunas "Stadip" de $12 \mathrm{~mm}$ de espesor, deja pasar la luz natural a tra. vés de los vitrales hacia el interior del templo y permite comprender la fisonomía de la fachada medieval antes de la adición del atrio (Fig. 14.b). El falso techo de la sacristía se interpretó desde los restos hallados, que se conservaron.

La restauración del patrimonio mueble se hizo desde el presupuesto de su reversibilidad máxima. Las obras sobre madera (tallas, pinturas sobre tabla y retablos), se protegieron contra la humedad de los paramentos y contra los insectos xilófagos. Se consolidaron mediante inyecciones de "Paraloid B-72", realizándose en los casos necesarios injertos y chuleteados con maderas más blandas que las de los soportes. Tras la eliminación de los repintes, se sentó el color aplicando con espátula calor y presión, previa protección de la capa pictórica con colleta y papel de seda. En la limpieza se utilizaron soluciones de amoníaco en agua al $3 \%$ y dimetil formamida y acetato de amilo al $50 \%$. Los restos de barniz y yeso se eliminaron con bisturí. La reintegración final se hizo a base de colores al barniz.

La decoración mural, en técnicas muy variadas, exigió diversas soluciones: la base de la pintura, muy disgregada y desprendida por la humedad y por los numero. sos picados, se consolidó con inyecciones de acetato de polivinilo. Las lagunas importantes se cubrieron con mortero de cal y arena para reforzar sus bordes, se estucaron y se trataron con tintas neutras. La limpieza se realizó por medios mecánicos como brocha y bis. turi o soluciones de amoníaco en agua. La reintegración de sectores pequeños, se hizo en función de la técnica pictórica original, con carboncillo, lápiz de color, pastel, temperas o pigmentos en acetato de polivinilo, utilizando en algunos casos el método de
"Regattino" vertical. La fijación se logró pulverizando "Paraloid B-72" diluido en disolvente nitrocelulósico. (Fig. 15.b).

La restauración de la iglesia se remató con acabados como una iluminación halógena cenital que evocando el misterio de las iglesias alumbradas con antorchas, permite seguir los textos litúrgicos. Se instalaron nuevos soportes para sagrario y altares y un conjunto de bancos donado por los feligreses (Figs. 10 y 12).

Iglesia, baptisterio, sacristía y atrio seguirán desempeñando las funciones para las que fueron edificadas. Las salas del S. XII, al norte del templo, podrán alojar una exposición sobre el monasterio.

\section{Intervención en el claustro}

Tras la demolición de casetas y corrales parásitos, se desarrolló una excavación arqueológica, que en la zona 4000 (Fig. 1), localizó estructuras de las épocas mozárabe y visigoda con gran potencia de niveles fértiles. Los arqueólogos hallaron las cimentaciones de las naves septentrional y oriental del claustro y la del peristilo de su galería, por lo que la posterior intervención arquitectónica pudo abordar la manifestación de sus límites edificando un pabellón sencillo pero de misión compleja en el contexto del monasterio. El perímetro de su planta libre se adaptó al de la nave oriental medieval desaparecida, utilizando en parte su cimentación. Su volumen y faldones de cubierta no repiten los originales, que se desconocen, sino que continuando los definidos por la Casa Rectoral y las salas laterales de la iglesia, recuperan por Levante el emplazamiento del muro interno de la galería (Figs. 16.a y 16.b.).

El pabellón preserva la zona arqueológica 4000 (Fig. 1), y facilita el acceso a la misma en excavaciones futuras. Albergará un depósito de libros, las salas de estudio y reunión de la escuela contigua y unos aseos públicos, sirviendo de local de apoyo a las actividades que se desarrollen en el claustro. Además, permitirá un doble paso en recodo desde la Plaza de España al claustro-ágora, ocultándolo desde aquélla. Su trazado, proporción, distribución en planta, materiales y disposición de huecos, responden al análisis de los elementos medievales conservados y sus soluciones constructivas son coherentes con las aplicadas en otras zonas del monasterio. 
En el ala occidental se restauró el osario protegiendo los restos de la humedad, dotándolos de mayor seguridad y facilitando su visita (Figs. 17.a y 17.b.).

Las intensas lluvias de diciembre de 1989, hicieron fracasar la ruinosa cubierta de propiedad privada del ala occidental. Fue adquirida por el Ayuntamiento, facilitándose una intervención de emergencia. La solución constructiva del nuevo tejado fue idéntica a la de las cubiertas de pabellón nuevo y atrio.

No se ha pavimentado el espacio libre del claustro. Deberá hacerse en el futuro reflejando mediante su dise- ño, niveles y materiales, el trazado de la antigua galería y el de la crujía norte cuya cimentación han documentado los arqueólogos. Ésta se elevará sobre aquélla, formando una escena.

La transformación llevada a cabo en Wamba, entre 1988 y 1991, ha garantizado la conservación de la iglesia durante los próximos años (ver foto, página 21) y ha detenido el deterioro del conjunto monástico, aportando datos desconocidos acerca de su historia y su morfología.

\section{Ficha técnica}

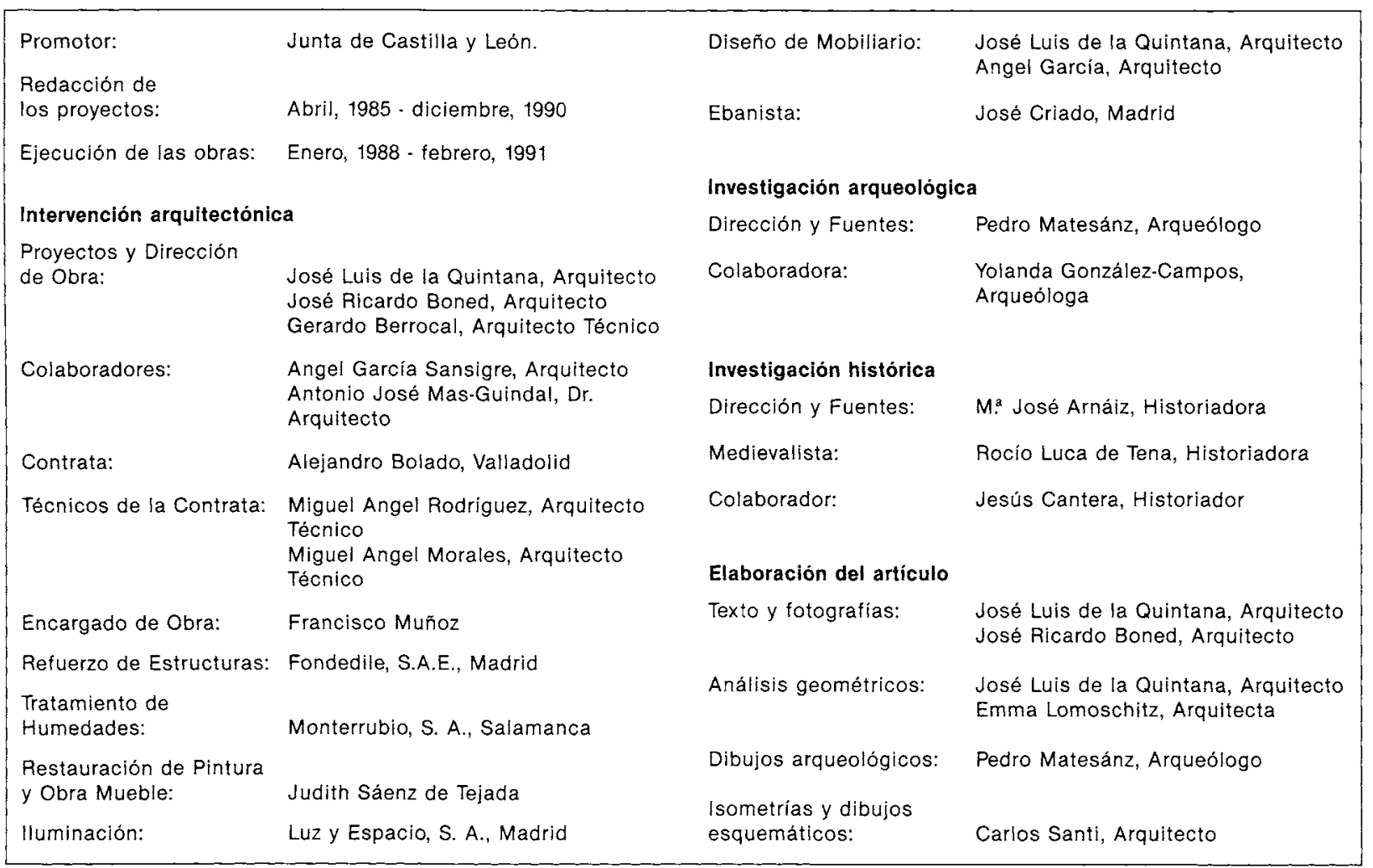

